\title{
From risk assessment to in-context trajectory evaluation - GMOs and their social implications
}

\author{
Vincenzo Pavone ${ }^{1 *}$, Joanna Goven ${ }^{2}$, Riccardo Guarino ${ }^{3}$
}

\begin{abstract}
Background: Over the past 20 years, genetically modified organisms (GMOs) have raised enormous expectations, passionate political controversies and an ongoing debate on how these technologies should be assessed. Current risk assessment procedures generally assess GMOs in terms of their potential risk of negatively affecting human health and the environment. Can this risk-benefit approach deliver a robust assessment of GMOs? In this paper, we question the validity of current risk assessment from both a social and an ecological perspective, and we elaborate an alternative approach, namely in-context trajectory evaluation. This paper combines frame analysis, context analysis and ecosocial analysis to three different case studies.

Results: Applying frame analysis to Syngenta's recent campaign 'Bring plant potential to life', we first de-construct the technosocial imaginaries driving GMOs innovation, showing how the latter endorses the technological fix of socioeconomic problems whilst reinforcing the neoliberal sociopolitical paradigm. Applying context analysis to biopharming in New Zealand, we then explore local practices and knowledge, showing that particularities of context typically omitted from risk assessment processes play a key role in determining both the risks and the potential benefits of a technology. Finally, drawing from the Italian case, we outline through ecosocial analysis how the lack of long-term studies, further aggravated by current methodological deficiencies, prevent risk assessment from considering not only how GMOs affect the environmental context but also, and most importantly, the way people live in, and interact with, this context.

Conclusion: Incorporating frame analysis, context analysis and ecosocial analysis, in the form of in-context trajectory evaluation, into the assessment of GMOs can improve the social compatibility, political accountability and ecological sustainability of its outcomes.
\end{abstract}

\section{Introduction}

Over the past 30 years, modern biotechnologies have raised enormous expectations as well as passionate political controversies, leading to a strong polarization in European societies, to permanent tensions with the USA about commercialization under World Trade Organization agreements and to an ongoing debate over risk assessment and risk management procedures. Mainstream risk assessment approaches conventionally understand risk assessment as 'a factually grounded, objective and value free analytic exercise' [1]. Consistent with this understanding, new technologies are typically assessed in terms of their potential risk of negatively

\footnotetext{
* Correspondence: vincenzo.pavone@cchs.csic.es

'Institute of Public Policies, CSIC - Consejo Superior Investigaciones

Científicas, Calle Albasanz 6-28, Madrid, 28037, Spain

Full list of author information is available at the end of the article
}

affecting human health and in terms of their environmental risks [2].

Risk assessment procedures, however, have not driven out all concerns about genetically modified organisms (GMOs), whilst doubts have been raised about the enormous pressures exerted by multinational corporations active in the fields of GMOs as well as about the conflicts of interest that may potentially affect the scientific experts working for regulating authorities like the European Food Safety Authority (EFSA). The independence and reliability of risk assessment procedures have been contested not only because they have often been carried out by the same multinational corporations producing the GMOs under evaluation but also because the original data, for commercial reasons, have not been released to the academic community [3].

\section{SpringerOpen ${ }^{\odot}$}

(C) 2011 Pavone et al; licensee Springer. This is an Open Access article distributed under the terms of the Creative Commons Attribution License (http://creativecommons.org/licenses/by/2.0), which permits unrestricted use, distribution, and reproduction in any medium, provided the original work is properly cited. 
Moreover, recent advances in genetics have highlighted the fact that the genome is a complex system, which, far from being a mechanistic sequence of genes independent of each other, can be considered as an ecosystem where all genes interact on a permanent basis [4]. This appreciation of the complexity of the genome has raised important questions about long-term and unpredictable consequences of genetic engineering [5], but the EFSA has not yet fully acknowledged this complexity and the attendant uncertainty. ${ }^{a}$ In addition, a number of independent studies on GMOs have recently questioned official assurances of safety on a number of specific points [6-11].

The universality, objectivity and neutrality of risk assessment methods have also been questioned, particularly in contexts of low scientific certainty, high stakes [12] and low social and political consensus [13]. Despite the fact that 'scientific representations of risk are routinely predicated on assumptions... which are not themselves scientific' and that 'scientific' risk assessments are 'inevitably hybrid judgements, dependent on both scientific and normative considerations' [14] EFSA continues to strictly characterise risk assessment as 'a scientific exercise' [15]. If 'science and values interact dynamically in the process of risk analysis, even at early stages when risks are first being assessed' [13], then scientific uncertainty requires judgement calls to be made, which will inevitably reflect the values of those making the calls. These judgement calls are typically embodied in criteria for acceptable technical data and methods. As pointed out by a United Nation Food and Agriculture Organization (FAO) expert on food safety, such criteria are imbued with values at a number of junctures; for example, risk characterisation may involve value-laden choices of parameters (e.g. between mortality or morbidity, between 'best practice' or 'typical use') and choices of extrapolation models (e.g. when moving from animal to human toxicity studies or when shifting from micro-ecosystems to farm-scale agricultural environments) [13]. Finally, risk assessment procedures also incorporate assumptions, obviously value-laden, on the significance given to the distribution of risks, on what constitutes a benefit worth taking a risk for and what level of risk is acceptable.

Not only can risk assessment not be value-free but it also cannot be divorced from consideration of the context(s) - both biophysical and sociopolitical - in which the technology is to be implemented. That is, assessing risk - identifying and estimating the nature, magnitude and likelihood of potential harms - must include consideration of social context, including the attitudes and practices of those (individuals and institutions) involved in managing risk. Localised neglect or flouting of risk management protocols, weak enforcement or monitoring procedures, ineffective norms, lack of transparency or reluctant authorities - all are relevant to risk assessment. In effect, risk assessment and risk management cannot be really separated. This is why it has been argued that risk assessment procedures cannot operate on the basis of technical expertise only: Lay expertise, users' expertise and social science expertise need to be taken into account $[16,17,5,18]$.

Finally, and crucially, risk assessment and risk management procedures typically operate only when the technology has already been developed and is ready for experimental and commercial authorization. Yet, at this stage the technology has already had an impact on society: Public and private resources have been invested; universities, companies and start-ups have been involved; promises have been made and social and political associations and movements have been mobilized [19]. All of these processes, which led to the actual technology being developed, have changed the innovation regime, the research agenda priorities, the actual allocation of public resources and even the perception of the problem for which this technology was first developed. Social and political values, therefore, are not only embedded in risk assessment procedures but they are also embedded in the very technology that risk assessment procedures try to evaluate.

\section{Frame analysis: GMOs are the solution, but what was the problem?}

Narrowing down the debate to whether GMOs constitute a threat to human health and the environment, risk assessment approaches have reduced the evaluation of GMOs merely to a question of how much risk a society can bear in exchange for the potential benefits claimed for the technology. Yet, there is much more to the implications of GMOs than the risk/benefit relationship suggests. This will be illustrated here by an examination of the current public relations campaign by Syngenta, in particular, of the way Syngenta frames the issue of GMOs.

Frames, in the social sciences, are 'principles of selection, emphasis and presentation composed of little tacit theories about what exists, what happens, and what matters' [20]. Framing is active at all times and is a function of our desire to control and master events that look complex at first sight. Frames help the analysts to order their experiences of reality into patterns of causes and effects so that a given problem can be understood and addressed. As a consequence, frame analysis should constitute a fundamental tool of policy studies and policy making because a better understanding of the frames used to make sense of a given problem is essential to evaluate the solution suggested to solve that problem [20]. It can, for example, help to identify when the 
proposed solution is an inappropriate 'technological fix', through which problems that have social, economic or political causes are framed and addressed in terms of a technological 'solution'. Such a solution claims to address unwanted effects but leaves untouched their non-technical origins.

Recently, Syngenta has implemented a campaign to promote societal support of GMOs in Europe. Syngenta's posters can be found in various buildings across Europe, mainly airports and public places. There are three posters related respectively to water scarcity, world hunger and child labour. The first poster (Figure 1) identifies the problem at stake as a growing scarcity of (fresh? unpolluted?) water and frames that problem as a function of water consumption by crops.

If this is the nature of the problem, then, it seems, we must choose between 'grow[ing] less food' and 'grow [ing] food that needs less water', and technological solutions to engineer plant varieties consuming less water not only make sense but appear as necessary and urgent:

'Providing enough food, feed, fiber and fuel for the world's population now and confronting future demands depend on whether currently available agricultural technology can be fully accessed by the world's farmers' (Syngenta website).

Framing water scarcity as a technical issue paves the

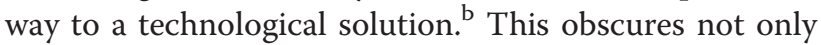
the whole array of social, economic and political factors that have resulted in the overuse of water and in the pollution of water that makes it unfit for use but also obscures the contribution to the problem of the very innovation regime of which Syngenta's strategy is a part. This regime, aimed primarily at industrialised agriculture in rich countries and deriving profits through intellectual property in those markets, has focused on the production of plant varieties that, in order to increase yield, require increased inputs in the form not only of pesticides but also irrigation. In many places, such varieties and methods have displaced low-input varieties and methods developed locally ([21]. The technological frame allows Syngenta to claim that consideration of such social, economic and political factors, and what they are likely to mean for any technology developed under this regime, is the problem: 'In effect, the rejection of sound science in assessing technology is denying food and income to those who would most benefit from new technologies' (Syngenta website).

In this way, Syngenta illustrates how framing social, economic and political problems as a technical question can result in the delegation of essentially political decisions to expert committees, which effectively divert responsibility from political actors to technoscientific networks by denying the normative dimensions of controversial issues [20]. A quote from Syngenta's website well illustrates this point:

'What is needed?

- Government officials must de-politicize their decisions on the use of technology in agriculture.

- Not only do we need governments to advance technology in developing markets, we also need governments to support the deployment of existing technologies across land currently under cultivation in order to raise yields and improve farming knowledge.'

As Syngenta's campaign demonstrates, 'objective' risk assessment approaches are often used to promote a technocratic approach to science and technology policy, which has been criticized on a number of political and sociological grounds [21-27]. For instance, such approaches neglect GMOs' impact on existing economic, political and social arrangements and on the developmental trajectory of the areas selected for

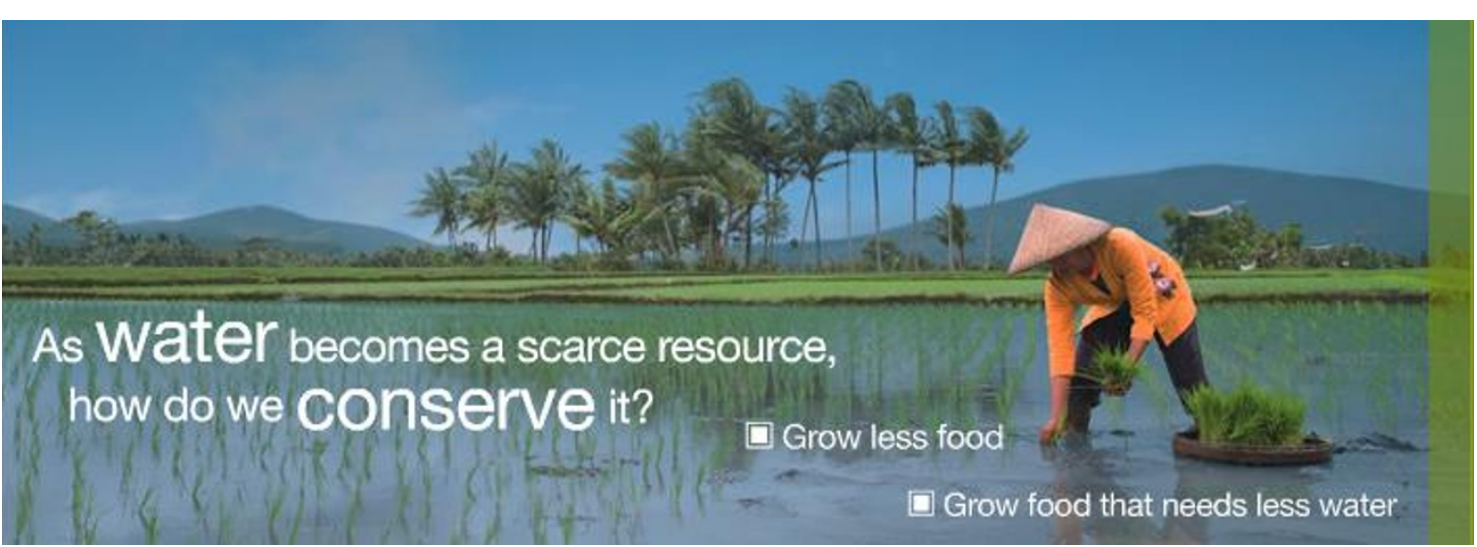

Figure 1 Water scarcity (source: http://www.singenta.com, ‘Bring plant potential to life' campaign). 
implementation [27]. As Sheila Jasanoff [28] puts it, technology shapes society and it is shaped by it in a mutually constitutive process of co-production where science, technology and social order emerge side by side.

The development of GMOs well illustrates this phenomenon: Syngenta's GM crops are a product of a sociopolitical context in which genetic traits can be patented. Without the reinterpretation of patenting criteria that occurred in the $1980 \mathrm{~s}^{\mathrm{c}}$, which extended patentability rights to plants and animals with modified genetic traits [29] the technique of genetic engineering may well have been developed as part of a larger basic research plan in molecular biology, but Syngenta's (and others') commercial GM crop plants would have never been developed. These GMOs could only have emerged a world in which western governments invest heavily in basic and applied research on biotechnologies in the attempt to build a 'knowledge-dense' bio-economy [30] that will maintain their competitiveness in relation to emerging economies like China, India and Brazil. GMOs appear meaningful only in a policy context where environmental and social problems are framed as technical so that technological (profitable) solutions can be elaborated, leaving unquestioned the actual causes of the problems at stake. This approach, which characterised the initial policy response to GMOs, can be detected even in more recent and reflexive assessment frameworks. For instance, the recently proposed problem formulation and options assessment method, which aims to provide a 'framework for identifying the crucial societal needs that could be satisfied by introducing a GM crop' [31], certainly helps to structure and facilitates the risk assessment by understanding and describing the receiving environments socioeconomically and ecologically [32]. Yet, its actual framing keeps endorsing a policy response where environmental and social problems are framed as technical so that technological (profitable) solutions like GMOs can be developed, leaving unquestioned the actual causes and factors that created those problems in the first place.

The point is that current approaches focusing on risk do not call into question the visions and imaginaries that sustain a given technology's trajectory [33,24]. Technological products are not neutral objects: They have been produced by specific actors, in specific contexts, in order to address a specific problem, which has been framed in such a way that given technologies make sense as solutions. As a result of the very process triggering their emergence, technologies are loaded with social and political values; they materialise certain paradigms; in fact, they 're-construct' social paradigms (ideas and assumptions about functioning) into physical matter. This will remain completely undetected as long as the focus of technology assessment concentrates on their risk implications.
A thorough analysis of the ethical, social and political values and principles that each technology carries through the visions and imaginaries it promotes, thus, is a fundamental step towards the inclusion into risk assessment processes of what has been defined by Helga Nowotny [23] as more socially robust knowledge. ${ }^{\text {d }}$ If social and political values are implicitly and explicitly embedded in a given technology's trajectory, risk assessment and risk management procedures need to incorporate those who can identify these embedded values and their implications, making them available for public and transparent discussion and deliberation. In contrast, risk assessment procedures take technologies for granted, non-technical expertise is not considered relevant and sociopolitical analyses about technology implementation are addressed as a problem per se. Syngenta argues:

'Regulation that is anything other than science-based will stifle innovation and limit the ability of farmers to grow more food with limited natural resources. Political pre-occupations are causing a crisis of governance in both the developed and the developing world.'

Rather than considering public concerns about GMOs as an opportunity to reconsider the technology from a different perspective, producing a wider and more robust assessment of GMOs' implications, promoters of GMOs in industry and government continue to position the public as the problem, calling for solutions that aim at reducing this opposition rather than at learning from it [34]. The concerns raised remain largely unaddressed, when not bluntly ignored [35], despite the proliferation of public engagement exercises, which seemingly expect public support for GM crops to grow simply as a result of increased dialogue and public participation [36].

Such approaches to public engagement have been challenged on a number of theoretical and empirical points, which relate, for instance, to who is 'the public' and how has it been constituted; who decides what is going to be talked about and on what grounds and at what stage of policy making is participation set and why $[37,38,35,24,39,27]$. In other words, 'the purpose is to hold science and industry answerable, with the utmost seriousness, to the fundamental questions of democratic politics [...] Who is making the choices that govern lives? On whose behalf? According to whose definitions of the good? With what rights of representation? And in which forums?' [40].

Despite these criticisms, risk assessment and public engagement exercises continue to treat the judgements of experts as 'scientific' and public contributions to the debate as 'perceptions', whilst the debate itself is highly restricted 'Risks are endlessly debated, whilst deeper questions about the values, visions and vested interests that motivate scientific endeavour often remain unasked or unanswered' [36]. Meanwhile, current regimes of 
science and technology innovation and the driving purposes and expectations shaping innovation and knowledge' [35]. are not subject to public debate and deliberation. On the one hand, questioning public 'perceptions' remains a dominant concern of public engagement exercises, which maintain their original purpose of reducing conflict and securing support for scientific innovation and expert-based policy making. On the other hand, questions about the reasons and the ways in which certain issues, and not others, have become objects of public policy, how and as a result of whose action has this happened and what kind of society are we trying to achieve through current innovation priorities are prevented from emerging as key issues in technology assessment procedures.

\section{Technology assessment in context}

Perhaps easier for technocratic risk assessors to understand, but still neglected within risk assessment processes, is the significance of the context of implementation for evaluating the risks and claimed benefits of a technology. Technologies never operate outside a biophysical and social context, and it is their interaction with their contexts that generates effects, impacts and implications. This is a statement of the obvious, yet its ramifications have yet to be fully recognised in risk assessment and other formal evaluations of technology. Put simply, in order to identify and evaluate the potential harms and benefits of a technology, we must know how it is likely to interact with its context, which requires knowledge of specific contexts as much as it requires knowledge of the technology itself.

Knowledge of specific contexts is unlikely to come from 'risk experts' or those with detailed knowledge of the technology derived from laboratory investigations and modelling. The kind of detailed knowledge of context necessary is often more experiential than formalised. People who are unfamiliar with the technology in question may nonetheless have knowledge of context that is highly relevant to assessing that technology. Such people are typically not involved in formal risk assessment processes.

There is ample evidence of the importance of contextual knowledge to evaluating risks. In Wynne's postChernobyl study of the interactions between Cumbrian sheep farmers and technoscientific personnel operating as risk managers, he found that the value placed by scientists on universally applicable models blinded them to the importance of local context. They ignored 'farmers' own knowledge of their local environments, hillsheep characteristics, and hill-farming management realities' [16]. This specialist hill-farming expertise, which was 'not codified anywhere' and was 'passed down orally and by apprenticeship' [16] in fact proved essential to predicting the behaviour of radioactive elements in the soil and to formulating competent strategies to manage the problem. Irwin's [17] discussion of the risk assessment of the organophosphate pesticide 2,4,5- $\mathrm{T}$ again highlights 'expert' blindness to local or experiential knowledge. In this case, the UK Advisory Committee on Pesticides (ACP) concluded that the pesticide was safe, provided it was used 'in the recommended way.' Farm workers, with knowledge of actual farm practices as well as of the social (power) relations involved, argued that it could not be judged safe because the prescribed precautions could not be taken in the actually existing contexts of use: 'the conditions envisaged by members of the [ACP] ... are impossible to reproduce in the field' [17].

There is also evidence of the importance of contextual factors to the realisation of claimed benefits. Outcomes of attempts to evaluate the performance and economic impact of GM crops in developing countries have been highly inconsistent. This, as Glover has shown in his survey of evaluations of 'pro-poor' effects of Bt cotton, is a result of abstraction from context:

'The efforts of analysts have been largely confounded... not only by the sheer complexity of the factors involved, but because the external variables they have struggled to control and exclude are actually essential to understanding the impacts of new crop varieties on farms. In other words, the strenuous efforts to rule out the effects of 'externalities' can be seen as a reflection of a basic failure to recognise the fundamental importance of contextual factors in complex socio-technical systems.' [41]

The relevant contexts include both biophysical factors (e.g. the local suitability of the background germplasm, seasonal rainfall, irrigation, soils, pest attacks and diseases) and sociopolitical factors:

'[S]eed choices, pest-management strategies, cropping patterns and farming systems are embedded in a particular household's or farmer's wider livelihood strategy, which in turn is embedded in a set of social and institutional relationships and processes.' [41]

The value of attending to specificities of context is illustrated here with examples from research exploring risks and potential benefits from implementing biopharming in New Zealand [42-44] Biopharming involves the production of plants and animals that have been genetically engineered to produce pharmaceutical substances (in, e.g. their leaves, seeds or milk) and the extraction and purification of those substances for use in humans. It is promoted as a lower-cost and more flexibly scalable production process. It is still unclear whether biopharming will be successful in these terms. Those who see biopharming as beneficial for New Zealand have portrayed it as a great opportunity for New Zealand farmers to add value to their products. The success of this strategy depends not only on the commercial success of biopharming as a drug production process but 
also on the practicalities of New Zealand farmers taking up biopharming.

Unlike other forms of drug production, biopharming poses the risk of contamination of the food supply, especially if the drug is made in a food-producing platform (such as food crop plants or cow, sheep or goat milk). The prevention of contamination requires strict containment. Farmers and others with practical experience of managing plants and animals and their products are an excellent source of knowledge relevant to whether or not strict containment on a 'biopharm' is feasible. Indeed, as suggested by Mauro et al. [45,46], farmer knowledge would appear to be a valuable source of information for the evaluation of agricultural technologies, including GM technologies, in general, yet it remains neglected by policy makers and researchers, especially in the global north. The farmers and others associated with the types of farming most likely to 'host' biopharming in New Zealand, that is, dairying and seed farming, identified a range of risk factors related to specificities of context. For example, the experience of those in seed farming suggested that complete containment in open-field conditions is impossible due to the impacts of wind, insects, birds and other animals. Most specialist seed farming in New Zealand is carried out in Canterbury, famous for its northwesterly winds, posing threats of cross-pollination. Although systems have been devised to minimise such contamination, local knowledge indicated that such systems are not adequate for the prevention of all contamination ${ }^{\mathrm{e}}$ :

'[I]n the Canterbury Plains, I don't know how you ever restrict that.... It's probably likely that the outcross is going to be not just 10 yards down the road, but probably $10 \mathrm{k}$ or $15 \mathrm{k}$ down the road. So $3 \mathrm{k}$ or $5 \mathrm{k}$ isolation's probably a waste of time.'

Long experience of particular crops produced observations that call into question the adequacy of proposed management regimes. For example, whilst the problem of persistence of viable seed in the soil is recognised, the experience of seed farmers suggests that it may be more intractable than typically acknowledged. Brassicas, as well as other oilseed crops, ryegrass and clover, were singled out as posing particular difficulties.

'If you have an oilseed crop, a Brassica crop, so a seed that has oil in it, [in] two years time it will be: oh, this crop is coming up again. And 20 years later perhaps: it's coming up again. And we're seeing that.'

'Clover's a bad news one because it can stay in 20 years. Rye grass, probably 10 years. Brassicas - forever, from my observation.'

It is often assumed that the risks posed by contexts can be mitigated by procedural requirements or controls imposed on the use of the technology. Observations such as those made above, however, suggest that technology assessments must take seriously the possibility that the context cannot be made safe enough. ${ }^{\text {f }}$

Moreover, the New Zealand research also questions the advisability of assuming that mandated controls will be consistently implemented. This, too, will be a function of context, both social and biophysical. Biopharming for farmers would be an economic activity like any other. This creates a situation in which there may be economic incentives to flout containment requirements. Farmers noted that rules are most often ignored when there is an economic incentive not to follow them. As with any product, increased market supply or reduced market demand may erode the profitability of the operation, whilst the existence of potentially competing production platforms $^{\mathrm{g}}$ [47-49] could bring about sudden increases in supply (and reductions in price). Biopharm animals may become ill, rendering them an economic liability. Costs to farmers may increase unexpectedly and render the contract less profitable. Such pressures experienced by a farmer directly or through his/her employer could provide an incentive not to follow the rules.

A relevant example supplied by dairy farmers of nonadherence to risk management rules involves herds containing tuberculosis-infected cows. Infected animals must be made readily identifiable, and there are restrictions on their movement. However, some farmers flout these rules, moving the infected herds without permission. Those involved in seed production noted that it is difficult to ensure that a combine harvester is completely clear of previously harvested plant material. Economic pressures might result in not cleaning harvesters as well as they perhaps should:

'Are you going to spend another three hours [cleaning the combine] in the sunshine, [when] you could be combining and the rain's forecast for the next day? Probably not ... I can give you the PC [politically correct] answer, 'no, no, we signed the documents and we'll do that.' I think in practical terms corners get cut.'

Such incentives are intertwined with ownership and management arrangements and with farmers' own assessments of and attitudes towards risks. Farmers' and other operators' own beliefs regarding the riskiness of an operation affect the likelihood that they will meticulously follow risk management protocols. That is, if a protocol is felt to be arbitrary or out of proportion to the risk as the farmer understands it, it may not be followed. This implies that the effectiveness of controls is to a significant degree reliant on farmer discretion. One example of this given by dairy farmers pertains to effluent disposal: They think 'oh, this will do', you know, 'the rules are that strict, but if we do this and this, it might be all right'.

In the seed sector, the demands of production and farmers' confidence in their own abilities may shape attitudes towards following rules: 
'Farmers tend - they're practical people cracking on with the job. So they're not looking at their ISO9000 quality control manual... It's not sloppiness or anything like that. But it's just the practical operation of things.'

Interviews with farmers also highlighted the ubiquity of human error. Interviewees could relate a litany of human error that occurs in everyday farming practice. The milk of cows being treated with antibiotics, for example, is meant to be kept out of the milk sold off the farm, and these cows are marked to indicate this. However, farmers cited cases of such markings coming off or just being missed by the person responsible for milking. These errors occur despite strong economic incentives to comply: Companies receiving the milk impose heavy financial penalties for farmers whose milk contains antibiotics.

As with potential harms, the assessment of (claimed) benefits, such as it is, rarely seeks detailed knowledge of the contexts with which the technology must interact if the benefits are to be realised. Yet potential adopters' understanding of their own situation is crucial to evaluating potential benefits. Biopharming is promoted to (and by) governments and regulators as bringing significant economic benefits to those jurisdictions and actors who engage in it. In New Zealand, biopharming has been framed as a solution to the problem of competitiveness in an economy dependent on commodity production and consequently as a bringer of new options and benefits to New Zealand farmers. ${ }^{\text {h }}$ On this basis, biopharming research and development have received generous public funding.

Specialty seed farmers and seed production companies, however, described a distribution of market power that militates strongly against seed biopharming returning major benefits to New Zealand [44,43]. With a similar distribution of power likely to obtain in the dairy sector, dairy farmers, who doubted it would be possible to combine biopharm and conventional cows in the same operation, would be reluctant to leave their existing supply relationships to venture into biopharming [42]. The practicalities of implementing biopharming, both in terms of measures to prevent contamination and in terms of relative distribution of market power, suggest that it is in fact unlikely that New Zealand farmers would benefit in any significant way from the introduction of biopharming. The likelihood and distribution of benefits are tightly linked not only to specificities of context, as argued here, but also to the processes of co-production discussed above: GMOs are a business strategy enabled through a particular intellectual property regime, and this drives both the framing of problems to which GMOs can be offered as a solution and the distribution (and nature) of benefits.

The implications of the different types of knowledge related here are diverse. Farmer knowledge of biophysical processes based on long experience of particular contexts is clearly relevant to assessing the potential impacts of biopharming and other agricultural GMO production. Farmer knowledge of their own economic position, e.g. their relative power in their commodity chain, is relevant to a more realistic assessment of promoters' claims of economic benefit. Both of these types of knowledge should be routinely integrated into assessment processes. Farmer knowledge of farmers' actual practices and of the economic and other circumstances that influence these is also relevant, primarily to assessing the adequacy of and likely compliance with management regimes, as is knowledge derived from interviews with farmers about their and others' attitudes towards the riskiness of biopharming (or GMOs) and thus towards the suitability of prescribed management practices. This suggests that rather than assuming that practitioner attitude and error are manageable through protocols and monitoring and that the existence of economic benefit can be read from the presumably rational intention of the applicant or adopter to deploy the technology, practitioner attitude and error as well as economic context should be viewed as integral to producing and therefore assessing, environmental and health risks. ${ }^{\text {i }}$

The case of biopharming also reinforces the more fundamental challenge for GMO (and, indeed, technology) governance regimes posed by the frame analysis. The business case for biopharming rests on the claims of cheaper drug production. Biopharming introduces a new (otherwise non-existent) hazard of pharmaceutical contamination of the food supply. Regulators have thus far failed to implement two obvious measures that would offer protection against such contamination - prohibiting the use of food organisms and requiring confinement to indoor production systems - presumably at least in part because they have been persuaded that it would seriously erode the profitability, and thus economic benefits, of biopharming. This decision highlights the importance of the fundamental question framed out of risk assessment processes: Does the purpose of the technology - understood not in terms of claimed, unproven benefits but in terms of the aims of the system that produced it - justify the risk that it is inevitably imposing?

\section{Ecosocial analysis}

GMOs affect the agri-food production system and have an impact not only on the environmental context into which they are introduced but also in the way people feel, live and interact with this context. For example, in many European countries, efforts have been made to support organic farming, small-sized farms, local products and cooperatives. This kind of territorial marketing has created a new ecosocial equilibrium in many 
rural communities, mitigating land abandonment and helping in the preservation of significant traits of so-called vanishing traditional landscapes. In such a context, GMOs and their regime of production and innovation will inevitably interact not only with the ecological but also the social equilibrium built on the ecological one. As a consequence, social analysis needs to be integrated with ecological studies on long-term environmental and ecosystemic changes affecting target farming areas. However, at least three main problems have so far prevented the integration of ecosocial analysis into risk assessment procedures: the lack of long-term studies, existing methodological deficiencies and a narrow, decontextualised approach to risks and benefits of GM crops.

The lack of long-term studies maintains a fairly high uncertainty in the assessment of risks for the environment and human health, strengthened by the unpredictability of some by-products of genetic manipulation [50]. For instance, Bt corn has been created through the insertion of the genes coding for the Cry toxins of Bacillus thuringiensis under specific promoters that were expected to act in the green parts of the plant, or in the pollen, but not in the roots [51]. Therefore, the steady occurrence of the toxin in the roots and exudates of $\mathrm{Bt}$ corn provides a good example of an unpredicted attribute (which also has potential long-term implications for the microbial fauna in the soil).

All the relevant literature on the environmental risks and benefits of the large-scale cultivation of GMOs compares the 'environmental performances' of transgenic crops vs. the conventional ones, but little attention is devoted to the long-term consequences of the observed changes in the frequency and distribution of commensal species (target and non-target organisms) at the ecosystem scale. There has not been time enough to produce sound results on such issues [52]. On the basis of this performance-based approach, modern agriculture became responsible of an ever-increasing trophic and ecological gap between cultivated areas and neighbouring ecosystems. Now, apart from introducing the specific hazards associated with genetic modifications, GM commercial crops perpetuate the very economic and social model of aggressive exploitation, intensive largescale cultivations and biodiversity reduction associated with conventional crops cultivated under modern agriculture principles. This is regrettable not only for aesthetical or scientific reasons linked to biodiversity conservation but also for the simple, utilitarian reason that the more we reduce and select the species co-occurring with the crops, the more we reduce the probability that there will be early bio-indicators of unanticipated risks and implications of the introduced technologies. In the last 50 years, natural early-warning signals were shown to be useful and effective instruments for the safeguard of human lives: For instance, the high toxicity and persistence of dichlorodiphenyltrichloroethane and polychlorinated biphenyls were identified in such way [53,54].

Natural macro-phenomena, and their changes and variations, may be considered, to a certain extent, predictable, but the more technology is able to transform the molecular characteristics of natural processes, the more the final outcome is unpredictable. This unpredictability proceeds from the existing gap between the pace regulating natural biological evolution, on the one hand, and the man-made technological evolution, on the other hand. Current nucleotide sequences are the result of biological evolution over three billion years. Changes in gene sequences may alter gene products, which have an impact on other genes and on other organisms: Each gene mutation triggers a series of spillover effects until a new equilibrium is reached in the homeostatic context of the ecosystem. Molecules are connected to the ecosystems thanks to the intrinsic ability of living matter to connect, interact and move towards more and more complex levels of integration. These processes do not repeat themselves indefinitely because the retroaction links responsible for preserving the homeostasis of the system are not completely self-contained but, rather, integrated in the evolutionary consistency of the biosphere.

In this respect, the ecosystem is not a complicated but a complex system. Complicated systems, though difficult to analyse, can be completely explored, provided that enough time and proper tools are available. Yet, complex systems, like biological ones, cannot be exhaustively analysed because their evolution is not predictable. In other words, whilst it is certainly possible to insert exogenous genes into a chromosome, it is impossible to predict and calculate the outcomes and the interactions that will follow over long periods. Traditional engineering customarily derives its certainty from measures and deterministic descriptions that allow for predictable results. Genetic engineering, in contrast, may well understand and quantify the productive performances of GMOs or their advantages in terms of a reduced need for fertilizers, but cannot predict or even foresee the medium- and long-term risks of introducing species that are alien to the global homeostatic equilibrium of the biosphere. Only natural selection processes will reveal beyond doubt whether these organisms will have been, from an evolutionary point of view, incorporated without major damages. Yet, this process is very slow, and its pace is certainly incompatible with market requirements.

It may be observed that not only in the case of GMOs but also at each breeding or cellular duplication casual 
mutations can happen, and these mutations are selected in the environment at individual level. Therefore, molecular effects of genetic manipulations are unpredictable like those of natural mutations occurring in natural breeding. Yet, there is a substantial difference that is not sufficiently considered in the actual case by case environmental risk assessment proposed by EFSA: The time needed to achieve a sufficient statistical power to detect possible effects of GMOs on the environment is substantially different between conventional and GM crops: Natural mutations and hybridization have been used to select the most desirable characters of cultivated plants since the very beginning of agriculture. So, any current statement on the environmental risks of conventional crops is based on very long-term observations, which cannot be automatically extended to the GMOs per analogy simply because apparently there's no difference in the frequency, variation and replication of mutations obtained through the insertion of homologous and heterologous genes. Another very critical statement of the EFSA procedure is that the duration of experiments to assess the risks to non-target organisms should be sufficient to reflect the pattern and duration of exposure that these organisms are likely to experience under field conditions [55-57]. Is this really feasible?

From a methodological perspective, current risk assessment methods evaluate GM risks on the basis of risk/benefit analysis and short-term environmental impact in comparison to conventional crops. Though necessary, this type of evaluation, which focuses on a direct cause-effect approach, falls short when environmental issues have to be addressed, for the homeostasis of the ecosystem is guaranteed by non-linear transformations. To date, we have accumulated significant evidence showing that environmental damage cannot be assessed through cost-benefit analysis, not only because the long-term impact cannot be easily predicted but also because the actual genetic modifications cannot be evaluated through simple calculations of causes and effects. Plant pathology, very much like human pathology, focuses more and more on degenerative alterations, which often emerge a long time after the exposure to the pathogenic agent has actually occurred [58]. As a result, not only is it incorrect to link xenobiotics and the actual damage in a cause-effect relationship but it is also misleading to consider that a substance, or a genetic expression, is non-toxic just because it does not interfere with a given metabolic process [59].

This situation is leading the European Union (EU) towards what we may call a 'biodiversity paradox'. On the one hand, it endorses and sponsors the development and implementation of GM commercial crops, which perpetuate and, allegedly, worsen the impact of largescale intensive industrial agriculture on the survival of the residual populations, plants and microorganisms existing in the agroecosystem. On the other hand, recognizing the threats to biodiversity and environmental preservation, the EU is setting up a strategy aiming at preserving biodiversity through the creation of protected ecosystems where residual and rare species are confined $[60,61]$ This paradox raises two main issues: First, it tends to confine biodiversity in restricted spaces, leaving the remaining agroecosystem permeable to GM crops, and second, the prospective protected ecosystems are not even big enough to be unaffected by external influences. This typically applies to Italy, where farm properties are relatively small and fragmented and the geomorphology of the territory makes the approach based on protected ecosystems unfeasible.

The Italian case is especially interesting because it presents a number of characteristics that call into question the applicability of risk assessment studies conducted in other nations. Italy, for instance, possesses a high biological diversity, which results from a great variety of climatic and environmental factors in a relatively small territory, mainly characterised by mountains, by the influence of the sea and by a prevalent orientation along the north-south line. It is generally accepted that to avoid cross-pollination and contamination, it is necessary to place GM crops on big portions of flat land, contained by a belt of similar, conventional, crops. In Italy, these conditions apply only to about $20 \%$ of the territory. Moreover, in Italy, there is still a significant variety of wild versions of cultivated crops, which makes the risk of contamination even higher than elsewhere. This remarkable territorial diversity is reflected in a noteworthy normative and administrative fragmentation. In Italy, there are more than 100 municipalities, grouped into dozens of provinces and 20 regions, which actually have different degrees of administrative and legislative autonomy. As the political answer to this coordination problem has been to attribute an ever-increasing autonomy to the local and regional administrations, this is shifting the whole responsibility, not only in territorial planning but also on the application of agricultural policies, to local authorities. This may well reduce the distance between citizens, firms and the administration authorities, but it also generates different views on goals and priorities pursued by these authorities, increasing rather than reducing, de facto, the coordination problem and the lack of an integrated, organic and consistent agricultural policy.

In such a context, characterised by serious coordination problems and a lack of an integrated agricultural strategy, a risk/benefit analysis merely focused on the performance comparison between GM and conventional crops may contribute important knowledge about some relevant features of GM commercial crops but will not 
be sufficient to evaluate the impact of GM crops on the local ecosystem (previously defined as the result of the interactions between social and natural elements) and on the social and economic arrangements that have been so far built on that specific ecosystem. By the same token, framing the debate on biotechnologies merely in terms of scientific and technical comparisons between GM and conventional crops not only runs the risk of endorsing a narrow contextualization of the assessment but it also fails to acknowledge the inherent complexity of ecological and social assessment strategies. How appropriate is it to promote or permit the cultivation of GM crops in a country whose culture and economy is based on local biodiversity, agricultural tourism, DOP (Protected Origin Denomination) productions, highquality wines and food? In fact, the economic success of these sectors would rather suggest the opposite strategy: invest even more in these sectors to renew and strengthen the international reputation of a country where ecological biodiversity is no less attractive, and indeed inextricably interlinked with, historical and cultural diversity.

The point here is not so much that GMOs are not a promising investment in the Italian social and economic context. Rather, we suggest that the assessment of the actual benefits of introducing GM commercial crops in a given ecosocial system should also take into considerations the specific ecological and socioeconomic peculiarities of the areas proposed for cultivation. In other words, the assurance of health and environmental safety plus the improved economic features of a GM commercial crop compared to the conventional alternative are not per se a sufficient motivation to authorize GM cultivation unless other ecological and social factors, specific to the prospective cultivation area, are also positively evaluated. Assessing GM commercial crops vis-à-vis different ecosocial areas may give rise to different outcomes because introducing GM crops in areas already extensively cultivated with conventional varieties in a massive industrial agriculture exploitation landscape where large-size farms constitute the dominant socioeconomic form of organization may not have the same ecosocial impact than introducing GM commercial crops where small-size farming of local varieties in a mountain-based landscape constitute the backbone of specific social and cultural institutions and life organizations. Our point is not that Italy should ban GMOs; rather, we argue that it is increasingly important to think in terms of an ecosocial equilibrium, whereby the ecological homeostatic equilibrium is part and parcel with the socioeconomic equilibrium reached around given cultivations, eating habits and farming practices, which have evolved during decades and are repositories of traditions, values, meanings and community life interactions. Whether this should be assessed on a country-by-country basis or by a common European agency is subject to an ongoing debate. Either way, what is of utmost importance is that the relationship between the ecological and the socioeconomic equilibrium is duly taken into consideration.

\section{Conclusions}

GMO assessment is a complex issue (not a complicated one), and risk assessment studies, no matter how sophisticated they are, cannot produce definite and unquestionable results because it is not merely a matter of an objective science delivering 'the facts'. In fact, risk assessment procedures embody social and political values and so do the technologies assessed. For a socially and scientifically more robust assessment, these values must be made explicit and taken into account when GM technologies are assessed. In this paper, thus, we have explored an approach to assessment of GMOs from a broader perspective, which not only highlighted the cognitive limits and the political implications of current risk assessment approaches but also took into consideration social, political, institutional and ecological elements.

First, we suggested the politics and ethics of a given technology be unpacked, by addressing the emergence, the sociotechnical networks, the power relationships and the economic interests that are tightly interrelated in the process of innovation and implementation. In this step - which addressed the question: what kind of future society is embedded in this technology? - the technosocial imaginaries and visions driving and underpinning technology innovation and implementation of Syngenta have been de-constructed and scrutinized, not only per se but also in relation to dominant sociopolitical imaginaries. Whilst GM producers patent their discoveries and impose royalties on their products, GMOs are framed as solutions to world hunger and environmental degradation. The debate therefore shifts to costs and benefits of GMOs, whilst the basic question of why GMOs were developed in the first place remains unanswered and, indeed, disappears into the background. Visions and imaginaries sustaining technological innovation do matter: Scientists' and companies' values need to be unpacked and analysed. In addition, it is time to incorporate non-technical expertise: Lay publics, social scientists and farmers have access to relevant societal knowledge that has to inform risk assessment. Frame analysis should, therefore, be deployed at the very upstream level, when a given technology is emerging as a potential opportunity to be considered for future investments.

In the second step - which addressed the question: in what kind of society is this technology going to be 
implemented? - we have shown the necessity of evaluating a technology in its proposed context of implementation, as well as the need to access locally based, experiential knowledge in order to do this. Social and institutional practices operating at local and national levels provide important information on how a given technology is likely to be implemented and to interact with other social and technical artefacts. Risk assessment procedures should focus not only on the safety of the technology but also on the safety of the context as a recipient of the technology [62] In this respect, our examples suggest that not only the biophysical and social elements of context but also the fundamental purpose of the technologies - in the sense of their driving forces or economic logic of development - as much as their technical capabilities are relevant to assessing potential harms and benefits. Context analysis, therefore, should complement and integrate current risk assessment procedures in order to produce a more comprehensive and socially robust knowledge about risks and potential benefits, which includes all those societal forms of knowledge currently excluded by risk assessment procedures on the grounds of their non-scientific nature.

In the third step - which addressed the question: how is this technology likely to affect the ecosocial equilibrium of the area in which it is going to be introduced? - ecosocial analysis was suggested. Social meanings, actions and relationships arise and are enacted around specific local environments and around the local understanding and framing of it. Changing these environments will inevitably change the sociorelational domains constructed around them. Therefore, ecosocial studies should study the impact of GMOs not only on the biophysical ecosystem but also on the social community that is part and parcel of that ecosystem. Ecosocial analysis, therefore, should guide policy makers in the third and final step, in which the suitability of given ecological areas for the introduction of GM crops is evaluated.

In sum, we argue that frame analysis, context analysis and ecosocial analysis should be performed along with the trajectory of the technology at stake and accompany the traditional risk assessment procedures to ensure social compatibility, political accountability and ecological sustainability. These three steps may help consolidate a more robust social assessment, which we define as an in-context trajectory evaluation.

\section{Endnotes}

${ }^{a}$ For more information, please refer to the EFSA Conference on 'GMO risk assessment for Human and Animal Health and the Environment', 14-15 September 2009, http://www.efsa.europa.eu/EFSA/efsa_locale-1178620753 812_1211902768091.htm.
${ }^{\mathrm{b}}$ The same logic is applied to world hunger (farmland is limited: how do we feed a growing population?) and to the relationship between poverty and education (our seeds enable children to spend more time in the classroom).

${ }^{\mathrm{c}}$ See the key US Supreme Court decisions, e.g. Chakrabarty vs. Diamond case (1980) and the US legislation, the Bayh Dole Act (1980).

d'Socially robust knowledge has three, interrelated aspects: it is tested for validity outside as well as inside the laboratory; it is most likely to be achieved by involving an extended group of experts; it results from having been repeatedly tested, expanded and modified' [[23], p.155].

${ }^{\text {e}}$ We note that the recent (July 2010) proposal of the European Commission that member states should have responsibility for decisions on cultivation of GMOs in their territories refers to the need to take into account regional and local factors, both agronomic and natural, when determining measures for coexistence or whether GMO-free areas should be created. Specific mention is made of, among other considerations, different 'climatic conditions (that influence the activity of pollinators and the transport of airborne pollen)' [62].

${ }^{\mathrm{f}} \mathrm{We}$ note that containment protocols established in various jurisdictions, including those proposed for biopharming, would not protect against contamination in the circumstances described here [47-49].

${ }^{g}$ That is, biopharm crops would compete economically with each other and with biopharm animals as 'production platforms' or 'bioreactors' producing therapeutic proteins, and both would compete with laboratory (vat) production. At least to date, biopharming is an alternative method for producing drugs that can already be produced in other systems, rather than a source of new drugs.

${ }^{\mathrm{h}}$ In other venues, particularly when in the midst of risk assessment processes with public input, biopharming is promoted as the path to curing disease, even though to date biopharm R\&D has focused on the production of generic versions of existing biopharmaceuticals.

${ }^{\mathrm{i}}$ It should be noted that EFSA not only recognises the potential usefulness of farmer knowledge in relation to post-release monitoring of GM plants but also demonstrates a failure to recognise the influence of practitioner attitude and economic context when it suggests that it is the farmers already growing the GMO who should be drawn upon for post-release monitoring of environmentally harmful effects of the GMO [15].

\footnotetext{
Author details

${ }^{1}$ Institute of Public Policies, CSIC - Consejo Superior Investigaciones Científicas, Calle Albasanz 6-28, Madrid, 28037, Spain ${ }^{2}$ School of Social and Political Sciences, University of Canterbury, Christchurch, New Zealand
} 
${ }^{3}$ Department of Botanic Sciences, Faculty of Mathematics, Physics and Natural Sciences, University of Palermo, Palermo, Italy

\section{Authors' contributions}

VP conceived the study and coordinated its design. He has mainly worked on the first section of the article, contributing with frame analysis, and coordinating and integrating the different sections of the article. He is also responsible for the final version of the article. JG has contributed with the second section on in-context analysis, and with the general and final editing of the article. RG has contributed with the third section on the eco-social analysis and helped on the conclusion, too. All authors read and approved the final manuscript.

\section{Competing interests}

The authors declare that they have no competing interests.

Received: 8 October 2010 Accepted: 2 February 2011

Published: 2 February 2011

\section{References}

1. Busch L, Grove-White $R$, Jasanoff S, Winickoff D, Wynne B: EC - measures affecting the approval and marketing of biotech products (WT/DS291, 292 and 293). Submitted to the Dispute Settlement Panel of the World Trade Organization. 2004 [http://www.ecolomics-international.org/ biosa_ec_biotech_amicus_academic2_ieppp_lancasteru_coord_0404.pdf], Accessed 03 May 2010

2. Davies H: Updated EFSA Guidance Document for the Risk Assessment of GM Plants and Derived Food and Feed Parma: European Food Safety Authority (EFSA); 2009 [http://www.efsa.europa.eu/en/events/documents/gmo090914p2.pdf], Accessed 21 April 2010

3. Johnson $\mathrm{KL}$, Raybould AF, Hudson MD, Poppy GM: How does scientific risk assessment of GM crops fit within the wider risk analysis? Trends Plant Sci 2007, 12:1-5.

4. Buiatti M: Le Biotecnologie Bologna: II Mulino; 2004

5. Giampietro M: The precautionary principle and ecological hazards of genetically modified organisms. AMBIO J Human Environ 2002, 31(6):466-470

6. Le Curieux-Belfond O, Vandelac L, Caron J, Séralini GE: Factors to consider before production and commercialization of aquatic genetically modified organisms: the case of transgenic salmon. Environ Sci Pol 2009, 12:170-189.

7. Séralini GE, Cellier D, Spiroux de Vendomois J: New analysis of a rat feeding study with a genetically modified maize reveals signs of hepatorenal toxicity. Arch Environ Contam Toxicol 2007, 52:596-602.

8. Séralini GE, de Vendômois JS, Cellier D, Sultan C, Buiatti M, Gallagher L, Antoniou M, Dronamraju KR: How subchronic and chronic health effects can be neglected for GMOs, pesticides or chemicals. Int J Biol Sci 2009, 5:438-443.

9. Gasnier C, Dumont C, Benachour N, Clair E, Chagnon, Séralini GE: Glyphosate-based herbicides are toxic and endocrine disruptors in human cell lines. Toxicology 2009, 262:184-191.

10. Heinemann J, Sparrow A, Traavik T: Is confidence in the monitoring of GE foods justified? TRENDS Biotechnol 2004, 22:331-336.

11. Traavik T, Heinemann J: Genetic engineering and omitted health research: still no answers to ageing questions. TWN biotechnology and biosafety series 7. 2007 [http://www.twnside.org.sg/title2/biosafety/pdf/ bio07.pdf], ISBN: 978-983-2729-76-1 Accessed 3 May 2010.

12. Funtowicz SO, Ravetz JR: Science for post-normal age. Futures 1992, 25:739-755.

13. Winickoff D, Jasanoff S, Busch L, Grove-White R, Wynne B: Adjudicating the GM food wars: science, risk, and democracy in World Trade Law. Yale J Int Law 2005, 30:82-121.

14. Millstone E: Science, risk and governance: Radical rhetorics and the realities of reform in food safety governance. Research Policy 2009, 38:624-636.

15. EFSA: Updated Guidance Document For The Risk Assessment Of Genetically Modified Plants And Derived Food And Feed. The EFSA Journal 2008, 727:1-135.

16. Wynne B: Misunderstood misunderstanding: social identities and public uptake of science. Publ Understand Sci 1992, 1:281-300.
17. Irwin A: Citizen Science: A Study of People, Expertise and Sustainable Development London: Routledge; 1995.

18. Liberatore A, Funtowicz SO: Democratizing expertise, 'expertizing' democracy: what does it mean, and why bother? Sci Publ Pol 2003, 30:146-150.

19. Van Lente $H$, Rip A: Expectations in technological developments: an example of prospective structures to be filled in by agency. In Getting New Technologies Together. Edited by: Disco C, van der Meulen BJR. New York: Walter de Gruyter; 1998:195-220.

20. Jasanoff S: Technology of humility: citizen participation in governing science. Minerva 2003, 41:223-244.

21. Jordan CF: Genetic engineering, the farm crisis and world hunger. BioScience 2002, 52:523-529.

22. Weingart P: Scientific expertise and political accountability: paradoxes of science in politics. Sci Publ Pol 1999, 26:151-161.

23. Nowotny $\mathrm{H}$ : Democratising expertise and socially robust knowledge. $\mathrm{SCl}$ Publ Pol 2003, 30:151-156.

24. Felt U (rapporteur): Taking European Knowledge Society Seriously. EUR 22700 Science \& Governance. ISBN-978-92-79-04826-5 Brussels, Belgium; 2007.

25. Levidow L: Democratizing agri-biotechnology? European public participation in AgBiotech assessment. Comp Sociol 2009, 8:541-564.

26. Ferretti MP: Risk and distributive justice: the case of regulating new technologies. Sci Eng Ethics 2009, 16:501-515.

27. Ferretti MP, Pavone V: What do civil society organisations expect from participation in science? Lessons from Germany and Spain on the issue of GMOs. Sci Publ Pol 2009, 36:287-229.

28. Jasanoff S, (Ed): States of Knowledge: The Co-production of Science and Social Order New York: Routledge; 2004.

29. Rouvroy A: Human Genes and Neoliberal Governance: A Foucauldian Critique New York: Routledge-Cavendish; 2008

30. OECD: The Bioeconomy to 2030: Designing a Policy Agenda Paris: International Futures Programme; 2009 [http://www.oecd.org/futures/ bioeconomy/2030], ISBN:978-92-64-03853-0. Accessed 22 April 2010.

31. GMO ERA Project report: GMO Guidelines Project. 2008 [http://www. gmoera.umn.edu/public/about_project/download/Final_report-sm.pdf], last accessed January 2011

32. Hilbeck A, Nelson $K$, Andow DA, Underwood E: A scientist's use of problem formulation and options assessment in risk assessment of GM crops. In Risk Hazard Damage. Edited by: Breckling B, Verhoeven R. Bonn: Federal Agency for Nature Conservation; 2004:131-145.

33. Macnaghten $P$, Kearnes MB, Wynne B: Nanotechnology, governance, and public deliberation: what role for the social sciences? Sci Comm 2005, 27:268-291.

34. De Boer M, McCarthy M, Brennan M, Kelly AL, Ritson C: Public understanding of food risk issues and food risk messages on the island of Ireland: the views of food safety experts. J Food Saf 2005, 25:241-265.

35. Wynne B: Public engagement as a means of restoring public trust in science - hitting the notes, but missing the music? Community Genet; 2006:9:211-220.

36. EC (European Commission): Public engagement in science: report of the science and society session. Research*eu; 2007

37. Jasanoff S: Designs on Nature: Science and Democracy in Europe and the United States Princeton: Princeton University Press; 2005.

38. Goven J: Processes of inclusion, cultures of calculation, structures of power. Sci Technol Hum Val 2006, 31:565-598.

39. Levidow L: European public participation as risk governance: enhancing democratic accountability for AgBiotech policy. Technol Soc 2007, 1:19-51.

40. Leach M, Scoones I, Wynne B: Science and Citizens: Globalization and the Challenge of Engagement. London: Zed Books; 2005.

41. Glover D: Undying Promise: Agricultural Biotechnology's Pro-poor Narrative, Ten Years on. STEPS Working Paper 15. Brighton: STEPS Centre; 2009, ISBN 9781858645808.

42. Goven J, Hunt L, Shamy D, Heinemann JA: Animal biopharming in New Zealand: drivers, scenarios and practical implications. Constructive conversations/Kōrero Whakaaetanga research report no. 12. 2008 [http:// www.conversations.canterbury.ac.nz/documents/animalbioreport.pdf], Accessed 3 May 2010.

43. Goven J, Campbell H, Cram F, Heinemann JA, Mackenzie A, Morris C, Phillips $\mathrm{H}$ : Biopharming in New Zealand: risk and governance implications. Constructive conversations/Körero Whakaaetanga research 
report no. 19. 2009 [http://www.conversations.canterbury.ac.nz/documents/ synthesis_report_final.pdf], Accessed 3 May 2010.

44. Morris C, Goven J, Heinemann JA, Hunt LM: Assessing plant biopharming in New Zealand: knowledge from the arable sector. Constructive conversations/Körero Whakaaetanga research report no. 18. 2009 [http:// www.conversations.canterbury.ac.nz/documents/ assessingplantbiopharmingfinal.pdf], Accessed 3 May 2010.

45. Mauro IJ, MCLachlan SM: Farmer knowledge and risk analysis: postrelease evaluation of herbicide-tolerant canola in western Canada. Risk Analysis 2008, 28:463-476.

46. Mauro IJ, McLachlan SM, Van Acker RC: Farmer knowledge and a priorì risk analysis: pre-release evaluation of genetically modified Roundup Ready wheat across the Canadian prairies. Environ Sci Pollut Res 2009, 16:689-701.

47. Canadian Food Inspection Agency: Developing a regulatory framework for the environmental release of plants with novel traits intended for commercial plant molecular farming in Canada. A discussion document developed by the Canadian Food Inspection Agency's Plant Biosafety Office. 2005 [http://www.inspection.gc.ca/english/plaveg/bio/mf/fracad/ commere.shtml], Accessed 1 October 2010.

48. Canadian Food Inspection Agency: Plants with novel traits (PNTs) approved confined research field trials, crop-specific terms and conditions.[http://www.inspection.gc.ca/english/plaveg/bio/confine.shtml], Accessed 1 October 2010.

49. APHIS: Supplemental permit conditions for permit \# 04-009-01r. 2004 [http://www.aphis.usda.gov/brs/aphisdocs/04_00901r_sc.pdf], Accessed 1 October 2010.

50. Schubert D: A different perspective on GM food. Nat Biotechnol 2002, 20:969.

51. Saxena D, Flores S, Stotzky G: Insecticidal toxin in root exudates from Bt corn. Nature 1999, 402:480-480.

52. Pignatti S, Guarino R: Gli OGM nell'ecosistema. In Le agrobiotecnologie nel contesto italiano. Edited by: Monastra G, Pastore G. Rome: INRAN; 2007:149-165.

53. Sheail J: Pesticides and Nature Conservation Oxford: Clarendon; 1985.

54. EEA (European Environment Agency): Late lessons from early warnings: the precautionary principle 1896-2000 Copenhagen: EEA; 2001, ISBN 92-9167-3234.

55. Perry JN, Rothery P, Clark SJ, Heard M, Hawes C: Design, analysis and statistical power of the farm-scale evaluations of genetically modified herbicide tolerant crops. J App Ecol 2003, 40:17-31.

56. Marvier M: Improving risk assessment for non-target safety of transgenic crops. Ecol Appl 2002, 12(4):1119-1124.

57. Marvier M, Van Acker RC: Can crop transgenes be kept on a leash? Front Ecol Environ 2005, 3:99-106.

58. Lorenzini G: Le piante e l'inquinamento dell'aria Bologna: Edagricole; 1999.

59. Cocucci SM: Effetti dell'inquinamento su sistemi agro-forestali: tecniche biologiche di monitoraggio e recupero Milan: Fondazione Lombardia per l'Ambiente; 1996.

60. Guarino R: Flora-fauna-habitat biotopes in Italy: policy and management issues. Ber R Tx Gesell 2008, 20:138-146.

61. Guarino R, Bazan G, Marino P: La sindrome delle aree protette. In Ricerca naturalistica, conservazione dell'ambiente e della biodiversità in Italia. Edited by: Moschini R, Pignatti S. Pisa: ETS; in press;

62. Goven J: Dialogue, governance, and biotechnology: acknowledging the context of the conversation. Integrated Assess J 2006, 6:99-116.

doi:10.1186/2190-4715-23-3

Cite this article as: Pavone et al:. From risk assessment to in-context trajectory evaluation - GMOs and their social implications. Environmental Sciences Europe 2011 23:3.

\section{Submit your manuscript to a SpringerOpen ${ }^{\circ}$ journal and benefit from:}

- Convenient online submission

- Rigorous peer review

- Immediate publication on acceptance

- Open access: articles freely available online

- High visibility within the field

- Retaining the copyright to your article

Submit your next manuscript at $>$ springeropen.com 